\title{
A Study on the Effect of Participation Performance on Platform Media: Sociodemographic and Technology Acceptance Factors
}

\author{
Mikyung $\mathrm{Kim}^{1}$ \\ ${ }^{1}$ Professor, Media Communication Department, Chungwoon University, S.Korea, \\ mkqueen67@gmail.com
}

\begin{abstract}
This study investigates the various factors that affect the participation performance (access, usage, platform utilization and data generation) of platform media. The variables considered in this study include: sociodemographic factors (age, gender, education, urbanity), Technology Acceptance Model (TAM) variables (perceived usefulness, perceived ease to use), perceived norms, and perceived reliability. The conclusions are based on the quantitative analysis of data obtained by conducting a structured online survey with 330 valid responses. The result of a t-test that gender has an influence on usage. Through regression analysis, it was found that age affects access, usage, platform utilization and data generation. It further finds that urbanity and education affect data generation. Also, perceived usefulness has an influence on participation performance as indicated from data generation. Perceived ease to use affects usage, platform utilization and data generation, and perceived norms affect data generation. Perceived reliability did not affect any of the participation performance variables. These research results have identified the causes and effects of the digital divide in the aspect of user's behavior of the platform into access, use, utilization, and data generation. Through this detailed behavioral analysis, it is possible to specifically approach how to resolve the digital divide. This study is intended to contribute to suggesting policy-making directions to bridge the digital divide.
\end{abstract}

Keywords: Sociodemographic Factors, Perceived Usefulness, Perceived Ease to Use, Perceived Norm, Perceived Reliability, Participation Performance of Platform Media

\section{Introduction}

Platform media is emerging as a new innovative media. Research on the relationship between the characteristics of platform media and the factors influencing adoption is insufficient. Therefore, it is important to close the performance divide between platform media users and stabilize the service by reviewing the factors influencing the participation behavior of platform media users.

The concept of the platform can be approached from three main aspects: hardware, software and applied software. Hardware platforms refer to physical structures that we encounter in various parts of real life. A software platform refers to an operating system on which various applications operate. Applied software platform refers to a service that has built its own ecosystem and has become a platform. Platform types can be classified by birth background. The platform defined in this study is related to services and refers to an applied software platform. Google and Naver are search engine-based platforms, while Amazon, Alibaba, and G-market are e-commerce-based platforms. SNS-based platforms include Facebook, Kakao Talk, and Instagram. Media video platforms include Wave, Netflix, TVing,

Received: September 16, 2021; $1^{\text {st }}$ Review Result: November 1, 2021; $2^{\text {nd }}$ Review Result: December 20, 2021 Accepted: January 29, 2022 
and YouTube. Companies such as Uber and Airbnb, which are shared platforms, can also be noted[1].

The platform is also called participatory media because of users' voluntary participation in data generation through interaction can generate useful information and knowledge. Users, knowingly or unknowingly, generate a variety of data through all online activities such as searching the Internet, using smartphones, watching videos, online shopping, hospital care, financial transactions, public transportation, and ordering food. The platform provides convenient services and information by utilizing data generated by users. As a representative participatory media, social media such as YouTube is creating a media ecosystem through the production and consumption of users. Participating media can be defined as media that can be user-centered, customized, and individualized with data and content produced by users. The participation of platform users becomes a source of value creation and competitiveness. The platform must create network effects through satisfactory interactions of many users. It is necessary to bring producers and consumers to the platform and promote their interaction[2][3].

Platform participation performance differs by sociodemographic factors. In most cases, men, young people, higher education, and high-income people tend to participate more online[3]. In addition, many scholars argue that based on the theory of information technology acceptance, user's media acceptance behavior should be verified in consideration of cultural factors and other external situations in the TAM that deal with beliefs, attitudes, and behavioral intentions. The TAM provides a high level of explanation for the adoption of new media[4]. In a platform media environment that combines digital technology and data, users need a higher level of learning and activity than in the past to effectively utilize the platform. The variables that affect the attitude presented in the TAM are also descriptive in the digital divide study[5][6]. In the TAM, socioeconomic and personal propensity factors were presented as factors that determined the intention of using technology and attitude toward using technology[4].

Whenever new media and new services were introduced, how users use media and service served as an important factor in establishing the media and service. However, despite this situation, no research has been conducted on the participation performance of users on the current platform. Therefore, based on the users' evaluation, value, and experience of existing media, this study researches the acceptance factors of platform media and examines how these factors affect platform media participation and behavior. First, this study examines how sociodemographic factors(age, gender, education, urbanity) affect the participation performance. Next, this study reviews the variables of the expanded TAM(perceived usefulness, perceived enjoyment, perceived norm, perceived value) and examines how these variables affect user's participation performance of platform.

\section{Literature Review}

\subsection{Sociodemographic Factors of Participation Performance in Platform Media}

The socioeconomic factors such as occupation, education, income and ethnic background in the new media environment have been found to be factors that affect the digital media performance[7].

Age has been shown to be roughly inversely correlated with platform usage[7-10]. Gender is a major factor indicating differences in platform participation performance. Schor et al[11], for instance, found that men participate in both a platform for artisanal working and for (micro-)entrepreneurs and start-up founders. However, women participate more on food swap platforms. Level of education appears to be one of the most crucial determinants of participation in the platform economy. Both Eurobarometer and Smith[7][8] states that people with a higher level of education are more likely to engage in the platform economy, either as providers or as consumers. ING (International Nederlanden Groep)'s survey also finds a strong correlation between education and the use of platforms[10]. The higher income (or higher employment status) correlates with participation in the platform performance[7][8]. Urbanity also seems to be strongly correlated to interest in the platform behaviors. Smith finds that US individuals residing 
in an urban environment are more likely to use various platforms[7]. Urbanity is a major factor in participation performance because the demand for services through platforms expands in densely populated urban areas.

H1. Sociodemographic factors(age, gender, education, urbanity) will affect platform participation performance of platform media.

\subsection{Technology Acceptance Model (TAM) and Perceived Norms and Perceived Reliability}

The TAM is a representative model for explaining and predicting an individual's adoption of information technology based on rational behavioral theory in the field of social psychology dealing with beliefs, attitudes, and behavioral intentions. As the validity of the measurement tool of the TAM proposed by Davis was verified, many studies have applied this model to the study of factors for adopting new media technology[12]. This model is characterized by a media user's perspective. It was found that people's behavioral intention to accept technology was determined by perceived ease of use and perceived usefulness, and that the influence of external variables on behavioral intention was mediated by perceived usefulness and perceived ease of use[4][13].

Meanwhile, the TAM has a disadvantage of emphasizing only the user's judgment on the technology. Therefore, an extended TAM is proposed by supplementing the shortcomings of the TAM and adding other variables to the TAM. Originally, the TAM analyzed the use and adoption of information technology through variables such as perceived usefulness, perceived ease of use, and intention to use. However, technical characteristics of information technology such as interactivity, quality, immediate accessibility, or user variables such as reliability, norms, pleasure, immersion, and self-efficacy also acted as external variables or parameters. In addition, socio-cultural factors and personal tendencies are also considered important external variables to be considered important [14-17].

The social factor, 'perceived norms', is the perceived pressure an individual receives to perform a specific behavior. Traditionally, the most commonly used variables representing these social influences are subjective norms, and image and visibility have also been treated as major variables that form social influences[18]. When interpreted from the perspective of the technology acceptance model, perceived norms means the degree of perception of social pressure as a measure of whether it would be better to use or not to use data-based platform services. Perceived reliability is an important empirical variable in forming, and developing relationships with customers[19]. Perceived reliability in terms of platform media use can be interpreted as player's predictions, expectations and satisfaction that the platform will provide the expected service. Regarding the impact of reliability on user's performance, Hoffman et al.[19] states that building reliability through cooperative interaction between web providers and consumers enables long-term exchange relationships.

H 2. The perceived usefulness, perceived ease to use, perceived norm, perceived reliability will affect participation performance of platform media.

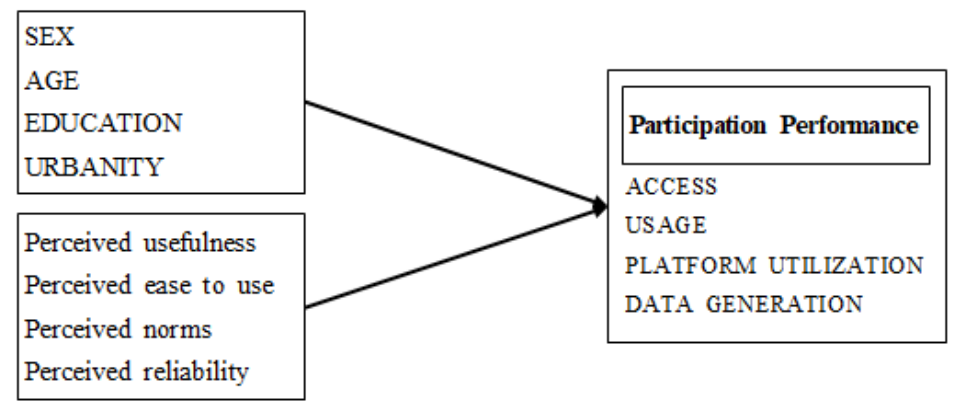

[Fig. 1] Research Design 


\section{Research Methodology}

\subsection{Data Collection}

This work investigates sociodemographic factors (age, gender, education, urbanity) and the TAM variables (perceived usefulness, perceived ease to use), perceived norms and perceived reliability. This paper investigates how these factors affect the participation performance of platform. The study used convenience sampling and the subjects answered a structured survey nationwide. The subjects' age ranges from 10's to 60's and they have experienced using various platforms. For two weeks from Aug. 1 to Aug. 15, 2020, this research received 330 valid responses via online survey. The data were verified using SPSS 25.0. In order to ensure the validity of the measurement scale of the variable, this study was confirmed by referring to the measurement scale that have been validated in previous studies.

[Table 1 ] Sociodemographic Character Frequency Analysis

\begin{tabular}{|c|c|c|c|}
\hline \multicolumn{1}{|c|}{ Sociodemographic Character } & Frequency & Percentage(\%) \\
\hline \multirow{3}{*}{ Sex } & Male & 192 & 58.4 \\
\cline { 2 - 4 } & Female & 138 & 41.6 \\
\hline \multirow{5}{*}{ Age } & 10 's & 18 & 5.5 \\
\cline { 2 - 4 } & 20 's & 117 & 35.5 \\
\cline { 2 - 4 } & 30 's & 90 & 27.3 \\
\cline { 2 - 4 } & 40 's & 45 & 13.6 \\
\cline { 2 - 4 } & 50 's & 48 & 14.5 \\
\hline \multirow{4}{*}{ Urbanity } & 60 's & 12 & 3.6 \\
\cline { 2 - 4 } & Major city (8 major cities) & 100 & 68.8 \\
\cline { 2 - 4 } & Small and medium-sized cities & 3 & 30.3 \\
\hline \multirow{5}{*}{ Education } & County & 10 & .9 \\
\cline { 2 - 4 } & Middle School & 87 & 3.0 \\
\cline { 2 - 4 } & High School & 195 & 26.4 \\
\cline { 2 - 4 } & Under graduate and Graduates & 38 & 59.1 \\
\hline
\end{tabular}

\subsection{Operational Definition and Variables}

Firstly, the study derived sociodemographic variables such as sex, age, urbanity and education from the sociodemographic character (cf. table 1). To investigate the effects of sociodemographic variables, this study referred to Andreotti et al. [20]. Then, perceived usefulness and perceived ease to use in the technology acceptance model and perceived reliability and perceived norms are identified (cf. table 2). The TAM and these two variables are constructed by transforming the variables of Jang \& Park[21] and were asked on a five-point scale. For platform performance, the four dependent variable such as access, usage, platform usage, data generation are identified (cf. table. 3). Participation performance variables are asked on a five-point scale by modifying the digital information divide index of National Information Society Agency[22].

[Table 2] The Operational Definition of TAM Variables and Perceived Norms and Perceived Reliability

\begin{tabular}{|c|c|c|}
\hline \multicolumn{2}{|c|}{ Variables } & Operational Definition \\
\hline TAM & Perceived usefulness & $\begin{array}{c}\text { The degree to which a person perceives that using platform would enhance } \\
\text { his or her job performance }\end{array}$ \\
\hline
\end{tabular}




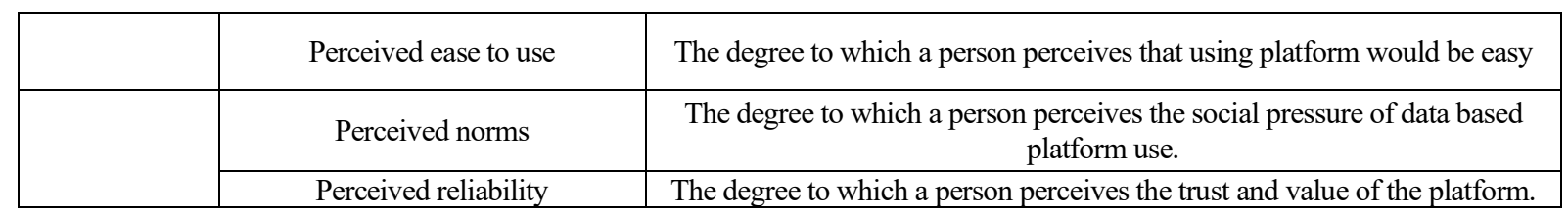

[Table 3] Participation Performance Variable and Operational Definition

\begin{tabular}{|c|c|c|}
\hline \multicolumn{2}{|c|}{ Variables } & Operational Definition \\
\hline \multirow{4}{*}{$\begin{array}{l}\text { Participation per- } \\
\text { formance }\end{array}$} & Access & $\begin{array}{l}\text { The degree to which a person has access to forms of information and com- } \\
\text { munication }\end{array}$ \\
\hline & Usage & $\begin{array}{l}\text { The degree to which a person uses an Internet-connected device for a vari- } \\
\text { ety of purposes. }\end{array}$ \\
\hline & Platform Utilization & $\begin{array}{l}\text { The degree to which a person uses the platform media for variety of pur- } \\
\text { poses }\end{array}$ \\
\hline & Data Generation & $\begin{array}{l}\text { The degree to which a person participates to generate data such as trading } \\
\text { data, mobile data, user behavior, sensing data and internet data. }\end{array}$ \\
\hline
\end{tabular}

\section{Research Results}

\subsection{Analysis of Reliability of Variables}

The reliability of each variables was measured through the Cronbach's $\alpha$ coefficient, which evaluates the internal consistency of the measurement scale. The reliability of the measurement scale was determined between .746 and .904 , except perceived norm (0.644).

[Table 4] Reliability Analysis of Variables

\begin{tabular}{|c|c|c|c|c|}
\hline Variables & Questions & $\begin{array}{c}\text { Cronbach's } \\
\alpha\end{array}$ & $\mathbf{M}$ & SD \\
\hline \multirow{3}{*}{$\begin{array}{c}\text { Perceived } \\
\text { Usefulness }\end{array}$} & Lower costs due to platform recommendations & \multirow{3}{*}{0.870} & \multirow{3}{*}{3.31} & \multirow{3}{*}{1.00} \\
\hline & Work efficiency with personalized needs support & & & \\
\hline & Customized useful information & & & \\
\hline \multirow{3}{*}{$\begin{array}{l}\text { Perceived } \\
\text { ease to } \\
\text { use }\end{array}$} & Platforms are easy to handle & \multirow{3}{*}{0.746} & \multirow{3}{*}{3.43} & \multirow{3}{*}{0.83} \\
\hline & Platform has convenience in connection and interaction & & & \\
\hline & Platforms give a sense of belonging and pleasure. & & & \\
\hline \multirow{2}{*}{$\begin{array}{c}\text { Perceived } \\
\text { norms }\end{array}$} & I am aware of the platform usage rules. & \multirow{2}{*}{0.644} & \multirow{2}{*}{3.58} & \multirow{2}{*}{0.83} \\
\hline & I am aware of the recommended platform usage rules & & & \\
\hline \multirow{5}{*}{$\begin{array}{l}\text { Perceived } \\
\text { reliability }\end{array}$} & Platform is fair & \multirow{5}{*}{0.804} & \multirow{5}{*}{3.21} & \multirow{5}{*}{0.85} \\
\hline & Platform is specialized & & & \\
\hline & Platform is accurate & & & \\
\hline & Platform is reliable & & & \\
\hline & Platform is free from regulation & & & \\
\hline \multirow{4}{*}{ Access } & Do you own desktop or notebook devices? & \multirow{4}{*}{$\mathrm{N} / \mathrm{A}$} & \multirow{4}{*}{5.72} & \multirow{4}{*}{1.29} \\
\hline & Do you own mobile devices? & & & \\
\hline & Do you have internet access? & & & \\
\hline & Do you have mobile internet access? & & & \\
\hline \multirow{3}{*}{ Usage } & Are you able to install, delete and update apps? & \multirow{3}{*}{0.904} & \multirow{3}{*}{3.71} & \multirow{3}{*}{0.86} \\
\hline & Are you able to connect wired and wireless internet? & & & \\
\hline & Are you able to set up web browser? & & & \\
\hline
\end{tabular}




\begin{tabular}{|c|c|c|c|c|}
\hline & Are you able to connect computer to an external device? & & & \\
\hline & Are you able to transfer files? & & & \\
\hline & Are you able to access and use public data? & & & \\
\hline & Are you able to interpret data? & & & \\
\hline \multirow{9}{*}{$\begin{array}{c}\text { Platform } \\
\text { utilization }\end{array}$} & Are you able to search proper information and news? & \multirow{9}{*}{0.797} & \multirow{9}{*}{3.64} & \multirow{9}{*}{0.72} \\
\hline & Are you able to use contents online? & & & \\
\hline & Are you able to use social network platforms? & & & \\
\hline & $\begin{array}{c}\text { Are you able to use accommodation, taxi, rental, shopping, video and game } \\
\text { platforms? }\end{array}$ & & & \\
\hline & Are you able to use cloud services? & & & \\
\hline & Are you able to use maps? & & & \\
\hline & Are you able to use public platforms? & & & \\
\hline & Are you able to post news, video, photographs, etc.? & & & \\
\hline & Are you able to post reviews and comments? & & & \\
\hline \multirow{4}{*}{$\begin{array}{c}\text { Data } \\
\text { generation }\end{array}$} & Are you able to share best place and rating? & \multirow{4}{*}{0.891} & \multirow{4}{*}{2.96} & \multirow{4}{*}{1.06} \\
\hline & Are you able to share location information? & & & \\
\hline & Are you able to share purchase information? & & & \\
\hline & Are you able to sharing Personal information? & & & \\
\hline
\end{tabular}

\subsection{Analysis of Participation Performance by Sociodemographic Character}

In the case of gender, the T-test was verified because sexes (male and female) is a nominal measure. Participatory performance of platform with respect to gender revealed that there was a significant sex difference in usage. It was $3.81(\mathrm{SD}=0.77)$ for males on average, and $3.58(\mathrm{SD}=0.97)$ for females $(\mathrm{t}=2.34, \mathrm{p}<0.05)$.

[Table 5] User's Participation Performance of Platform by Gender

\begin{tabular}{|c|c|c|c|c|c|c|}
\hline & & $\mathbf{N}$ & $\mathbf{M}$ & SD & $\mathbf{t}$ & $\mathbf{p}$ \\
\hline \multirow{2}{*}{ Access } & Male & 192 & 5.78 & 1.13 & \multirow{2}{*}{.907} & \multirow{2}{*}{.365} \\
\hline & Female & 138 & 5.64 & 1.48 & & \\
\hline \multirow{2}{*}{ Usage } & Male & 192 & 3.81 & 0.77 & \multirow{2}{*}{2.336} & \multirow{2}{*}{$.020^{*}$} \\
\hline & Female & 138 & 3.58 & 0.97 & & \\
\hline \multirow{2}{*}{$\begin{array}{l}\text { Platform } \\
\text { utilization }\end{array}$} & Male & 192 & 3.64 & 0.71 & \multirow{2}{*}{-.141} & \multirow{2}{*}{.888} \\
\hline & Female & 138 & 3.65 & 0.74 & & \\
\hline \multirow{2}{*}{$\begin{array}{c}\text { Data } \\
\text { representation }\end{array}$} & Male & 192 & 2.87 & 1.04 & \multirow{2}{*}{-1.772} & \multirow{2}{*}{.077} \\
\hline & Female & 138 & 3.08 & 1.08 & & \\
\hline
\end{tabular}

$* \mathrm{p}<.05, * * \mathrm{p}<.01, * * * \mathrm{p}<.001$

As the result of regression analysis, age has been shown to have a negative effect to the access $(\beta=-.321, p<0.001)$, the usage $(\beta=-.311, p<0.001)$, the platform utilization $(\beta=-.221, p<0.001)$ and the data generation $(\beta=-.178, p<0.001)$. Urbanity has a significant positive effect $(\beta=.158, p<0.001)$ on the data generation divide. Education has a significant negative impact $(\beta=-.143, p<0.001)$ on the data generation. The more urbanized one is, the better one generates and reproduces data. The younger one is, the better one accesses and uses platform media, and the higher the utilization of the platform. One is also good at generating data. It can be seen that the higher the level of education, the more careful one 
is to generate and represent data.

[Table 6] User's Participation Performance of Platform by Urbanity, Age, Education and Income

\begin{tabular}{|c|c|c|c|c|c|c|c|c|c|c|c|c|}
\hline & \multicolumn{3}{|c|}{ Access } & \multicolumn{3}{|c|}{ Usage } & \multicolumn{3}{|c|}{$\begin{array}{c}\text { Platform } \\
\text { Utilization }\end{array}$} & \multicolumn{3}{|c|}{$\begin{array}{c}\text { Data } \\
\text { generation }\end{array}$} \\
\hline & $\boldsymbol{\beta}$ & $\mathbf{t}$ & p & $\boldsymbol{\beta}$ & $\mathbf{t}$ & $\mathbf{p}$ & $\boldsymbol{\beta}$ & $\mathbf{t}$ & $\mathbf{p}$ & $\boldsymbol{\beta}$ & $\mathbf{t}$ & $\mathbf{p}$ \\
\hline Urbanity & .003 & .058 & .954 & -.020 & -.359 & .720 & .012 & .212 & .832 & .158 & 2.93 & $.004 * *$ \\
\hline Age & -.321 & -5.41 & $\begin{array}{c}.000^{* *} \\
*\end{array}$ & -.311 & -5.44 & $\begin{array}{c}.000^{* *} \\
*\end{array}$ & -.222 & -3.75 & $\begin{array}{c}.000^{* *} \\
*\end{array}$ & -.178 & -3.20 & $.001 * *$ \\
\hline Education & .079 & 1.340 & .181 & .105 & 1.857 & .064 & .026 & .450 & .653 & -.143 & -2.60 & $.010^{*}$ \\
\hline $\mathbf{R 2}$ & \multicolumn{3}{|c|}{.092} & \multicolumn{3}{|c|}{.156} & \multicolumn{3}{|c|}{.096} & \multicolumn{3}{|c|}{.204} \\
\hline adjusted R2 & \multicolumn{3}{|c|}{.069} & \multicolumn{3}{|c|}{.135} & \multicolumn{3}{|c|}{.073} & \multicolumn{3}{|c|}{.184} \\
\hline $\mathbf{F}$ & \multicolumn{3}{|c|}{$3.993 * * *$} & \multicolumn{3}{|c|}{$7.307 * * *$} & \multicolumn{3}{|c|}{$4.171 * * *$} & \multicolumn{3}{|c|}{$10.116^{* * *}$} \\
\hline
\end{tabular}

\subsection{Analysis of Participation Performance of Platform Media by Perceived Usefulness, Perceived Ease to Use, Perceived Norms and Perceived Reliability}

As the result of regression analysis, perceived usefulness has been shown to have a statistically significant positive $(+)$ effect $(\beta=.170, \mathrm{p}<0.05)$ on the data generation. Perceived ease to use has been shown to have a statistically significant positive $(+)$ effect $(\beta=.580, \mathrm{p}<0.001)$ on the usage, positive $(+)$ effect $(\beta=.428, \mathrm{p}<0.001)$ on platform utilization and positive $(+)$ effect $(\beta=.823, \mathrm{p}<0.001)$ on data generation. Perceived norms has been shown to have a statistically significant negative (-) effect ( $\beta=.241$, $\mathrm{p}<0.001$ ) on data generation. Perceived reliability does not affect platform performance. Perceiving the usefulness of platform media means that users usefully perceive customized services represented by data. As a result of users' perception that it is easy to use, it was found that it does affect the use of platform media and data services. Perception of platform usage norms particularly affects data generation. Since the representation of data is related to privacy, perceived norm affects data generation.

[Table 7] User's Participation Performance of Platform by Perceived Usefulness, Perceived Enjoyment, Perceived Norm and Perceived Reliability

\begin{tabular}{|c|c|c|c|c|c|c|c|c|c|c|c|c|}
\hline & \multicolumn{3}{|c|}{ Access } & \multicolumn{3}{c|}{ Usage } & \multicolumn{3}{c|}{$\begin{array}{c}\text { Platform } \\
\text { utilization }\end{array}$} & \multicolumn{3}{c|}{$\begin{array}{c}\text { Data } \\
\text { generation }\end{array}$} \\
\cline { 2 - 12 } & $\boldsymbol{\beta}$ & $\mathbf{t}$ & $\mathbf{p}$ & $\boldsymbol{\beta}$ & $\mathbf{t}$ & $\mathbf{p}$ & $\boldsymbol{\beta}$ & $\mathbf{t}$ & $\mathbf{p}$ & $\boldsymbol{\beta}$ & $\mathbf{t}$ & $\mathbf{p}$ \\
\hline $\begin{array}{c}\text { Perceived } \\
\text { usefulness }\end{array}$ & -.072 & -.859 & .391 & -.015 & -.203 & .840 & .017 & .220 & .826 & .170 & 2.559 & $.011 *$ \\
\hline $\begin{array}{c}\text { Perceived } \\
\text { ease to use }\end{array}$ & .102 & 1.039 & .299 & .508 & 5.75 & $\begin{array}{c}.000^{*} \\
* *\end{array}$ & .428 & 4.887 & $\begin{array}{c}.000^{*} \\
* *\end{array}$ & .636 & 8.235 & $\begin{array}{c}.000^{*} \\
* *\end{array}$ \\
\hline $\begin{array}{c}\text { Perceived } \\
\text { norms }\end{array}$ & .147 & 1.827 & .069 & -.001 & -.016 & .987 & .023 & .320 & .749 & -.241 & -3.791 & $\begin{array}{c}.000^{*} \\
* *\end{array}$ \\
\hline $\begin{array}{c}\text { Perceived reli- } \\
\text { ability }\end{array}$ & -.036 & -.474 & .636 & -.058 & -.860 & .391 & .027 & .397 & .692 & .020 & .334 & .738 \\
\hline R2 & \multicolumn{3}{|c|}{.030} \\
\hline Adjusted R2
\end{tabular}




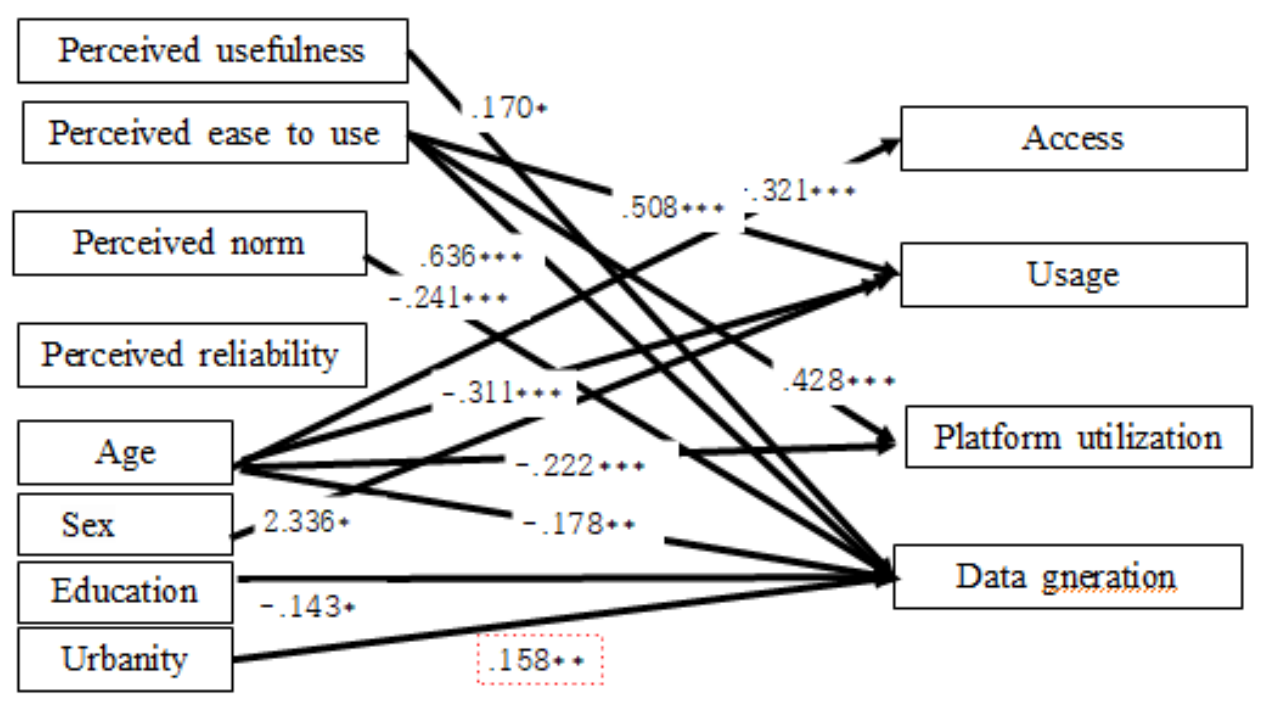

[Fig. 2] Result of Research Design

\section{Conclusion}

Platform media that has emerged as a result of data technology requires a higher level of utilization while providing new values and efficacy that existing media failed to provide. In order to fully explain users' acceptance of platform media in a new media use environment, it is necessary to approach sociodemographic attributes, technology acceptance models, and socio-cultural adoption factors. The research hypothesis suggested that age, sex, education, and urbanity would affect platform performance. In addition, perceived usefulness, perceived ease to use, perceived norms, and perceived reliability would also have an effect. . The main research results and implications of this study are summarized as follows.

As a result of the study, gender was only seen to have a direct effect on usage competency. Education level and data presentation showed a negative(-) correlation to data generation. Urbanity had a positive $(+)$ effect only on data generations. Also, perceived usefulness had a positive $(+)$ effect on data generation among platform performance factors. Perceived ease to use had a positive $(+)$ effect on usage, platform utilization, and data presentation. Perceived norms negatively(-) affected data generation. As a result of the influence of sociodemographic factors, age had a negative(-) effect on access, usage, and platform utilization, and data presentation.

The results of the above sociodemographic attributes showed that men have better platform usage ability than women, just as gender is related to technology-friendly behavior. However, if the level of education is high in platform use behavior, it is interpreted that there is a tendency to be aware of the risk of personal information protection in relation to the platform's data-based customized services. In addition, it was found that urban areas are positively accepting data generation by using various platforms such as commercial and delivery platforms. In the case of age, it shows that adolescents are much more friendly and actively accepting new media technologies. These research results are similar to the demographic acceptance results of existing new technology acceptance studies[21].

The above research results on TAM (perceived usefulness, perceived ease to use) and socio-cultural variables (perceived norms, perceived reliability) are interpreted as indicating that the reason users perceive a platform as being useful is because the platform provides customized services to users based on data. It was found that a user's impression of the ease of use the platform positively affects their using platform devices, utilizing platform media, and generating data. In other words, users showed higher 
use and utilization of platforms and data as a function of convenience than they did based on the usefulness of platform media services. Both platform usefulness and ease of use were found to have an effect on platform performance such as data generation. This is interpreted as highly appreciating the value of data on the platform when it is recognized as easy and useful. The perception of norms on the platform negatively affects the platform's data generation, which means that users recognize that the platform's data generation can negatively affect personal information protection. The reliability of the platform did not actually affect any platform performance. Except for the research results that the perception of platform reliability does not actually affect platform performance, the results of this study were similar to the existing research results[22] in terms of acceptance behavior.

The importance of this study is to examine the relationship between sociodemographic attributes and technology acceptance models and socio-cultural variables in the platform data environment.

First, by grasping that sociodemographic attributes affect platform usage behavior, it will be possible to contribute to suggesting the cause of the digital divide in platform media and the direction of policy establishment to bridge the digital divide as a follow-up study.

Second, in addition to the TAM variables of platform media, the influence of platform use behavior was examined by comprehensively reflecting the perceived norms and perceived reliability. However, it is necessary to check the influence by setting the technology acceptance variable as an internal variable and the socio-cultural variable as an external variable.

Third, most of the studies on the attitude of accepting new media mainly studied attitudes and behaviors. However, this study approached the platform by subdividing the behavior of the platform into access, use, utilization, and data generation. Through this detailed behavioral analysis, it is possible to specifically approach how to resolve the digital divide.

Finally, this study approached the adoption of new platform media in depth, but there are limitations. In future studies, the causal relationship of platform behavior can be interpreted abundantly through research on the relationship between various external factors and technology acceptance models.

\section{References}

[1] Dohoon Kim, Conceptual Typology for Platform Service Ecosystems, Journal of Information Technology Services, (2016), Vol.15, No.3, pp.299-319, DOI: 10.9716/KITS.2016.15.1.299

[2] T. Correa, The Participation Divide Among “Online Experts": Experience, Skills and Psychological Factors as Predictors of College Students' Web Content Creation, Journal of Computer Mediated Communication, (2010), Vol.16, No.1, pp.71-92, DOI: 10.1111/j.1083-6101.2010.01532.x

[3] E. Hargittai, G. Walejko, The participation divide: Content creation and sharing in the digital age, Information, Communication and Society, (2008), Vol.11, No.2, pp.239-256, DOI: 10.1080/13691180801946150

[4] F. D. David, Perceived usefulness, perceived ease of use, and user acceptance of information technology, Management Information Systems Quarterly, (1989), Vol.13, No.3, pp.319-340, DOI: https://doi.org/10.2307/249008

[5] J. Schradie, The digital production gap: The digital divide and Web 2.0 collide, Poetics, (2011), Vol.39, No.2, pp.145168, DOI: 10.1016/j.poetic.2011.02.003

[6] J. Warehem, A. Levy, W. Shi, Wireless diffusion and mobile computing: Implications for the digital divide, Telecommunications Policy, (2004), Vol.28, No.5-6, pp.439-457, DOI: 10.1016/j.telpol.2003.11.005

[7] http://www.pewinternet.org/2016/05/19/the-new-digital-economy/, Nov 07 (2021)

[8] http://www.pewinternet.org/2016/05/19/the-new-digital-economy/, Oct 14 (2021)

[9]https://www.pwc.com/gx/en/news-room/press-releases/2021/pwc-generation-unlimited-unicef-report-reachingyes.html, OCT 30 (2021) 
[10] https://www2.deloitte.com/ch/en/pages/consumer-business/articles/the-sharing-economy.html, Nov 11 (2021)

[11] J. B.Schor, C. Fitzmaurice, L. B. Carfagna, W. Attwood-Charles, E. D. Poteat, Paradoxes of openness and distinction in the sharing economy, Poetics, (2016), Vol.54, pp.66-81, DOI: 10.1016/j.poetic.2015.11.001

[12] F. D. Davis, R. P. Bagozzi, Extrinsic and Intrinsic Motivation to Use Computers in the Workplace, Journal of Applied Social Psychology, (1992), Vol.22, No.14, pp.1111-1132, DOI: 10.1111/j.1559-1816.1992.tb00945.x

[13] V. Venkatesh, F. D. Davis, A Theoretical Extension of the Technology Acceptance Model: Four Longitudinal Field Studies, Management Science, (2000), Vol.46, No.2, pp.186-204, DOI: 10.1287/mnsc.46.2.186.11926

[14] V. Venkatesh, Creation of favorable user perceptions: Exploring the role of intrinsic motivation, Management Information Systems Quarterly, (1999), Vol.23, No.2. pp.239-260, DOI: 10.2307/249753

[15] B. Greenberg, Gratifications of Television viewing and their correlates for British children, The Use of Mass Communication: Current Perspectives on Gratifications Research, Sage Publications, pp.71-92, (1974)

[16] A. Eggert, W. Ulaga, Customer perceived value: a substitute for satisfaction in business markets?, Journal of Business \& Industrial Marketing, (2002), Vol.17, No.2/3, pp.107-118, DOI: 10.1108/08858620210419754

[17] R. N. Rimal, K. Real, Understanding the Influence of Perceived Norms on Behaviors, Communication Theory, (2003), Vol.13, No.2, pp.184-203, DOI: 10.1111/j.1468-2885.2003.tb00288.x

[18] I. Ajzen, The Theory of Planned Behavior, Organizational Behavior and Human Decision Process, (1991), Vol.50, No.2, pp.179-211, DOI: 10.1016/0749-5978(91)90020-T

[19] D. L.,Hoffman, T. P., Novak, M. Peralta, Building consumer trust online, Communications of the ACM, (1999), Vol.42, No.4, pp.80-85, DOI: 10.1145/299157.299175

[20] A. Andreotti, G. Anselmi, T. Eichhorn, C. P. Hoffmann, M. Micheli, Participation in the Sharing Economy, SSRN Electronic Journal, (2017), pp.1-40, DOI: 10.2139/ssrn.2961745

[21] Yongho Chang, Jonggu Park, Adoption Model of Microblog: An Integrated Approach to Media Adoption Studies, Korean Journal of Journalism \& Communication Studies, (2010), Vol.54, No.5, pp.32-58, UCI: G704000203.2010.54.5.004

[22] The Report on the Digital Divide, Ministry of Science and ICT, pp.1-519, (2020), https://www.msit.go.kr/bbs/view.do? sCode $=$ user\&mId $=99 \& \mathrm{mPid}=74 \&$ pageIndex $=\&$ bbsSeqNo=79\&nttSeqNo $=3173382 \&$ searchOpt $=\mathrm{ALL} \& \operatorname{searchTxt}=$ 